\title{
Pricing, Patent Loss and the Market for Pharmaceuticals*
}

\author{
RICHARD G. FRANK \\ DAVID S. SALKEVER \\ Johns Hopkins University \\ Baltimore, Maryland
}

. . . whole drugs which the best employed apothecary, in a large town, will sell in a year, may not perhaps cost him above thirty or forty pounds. Though he should sell them, therefore for three or four hundred, or at a thousand percent profit, this may frequently be no more than reasonable wages...

Adam Smith

The Wealth of Nations, 1776

\section{Introduction}

Over the past twenty years public policy makers have often attempted to balance concerns over price levels of prescription drugs with the desire to encourage innovation in the pharmaceutical industry. The Drug Price Competition and Patent Term Restoration Act of 1984 very clearly reflects the determination of policy makers to simultaneously address issues of price control and technical progress. The 1984 Act increased returns to innovation by extending the period of patent protection to take into account the time between receipt of a patent and Food and Drug Administration (FDA) approval of a drug for sale in the market.

The 1984 Act also reduced the testing requirements for approval of new generic brands of existing chemical entities, thus reducing entry barriers in markets where patents have expired. The expected outcome from eased entry conditions for generic substitutes was substantially enhanced price competition and lower prices for brand name drugs. In fact, prices for brand name drugs have tended to increase following entry by generics. Wagner and Duffy [28] examined price changes for top selling generics and name brands. They show substantial price increases in brand name prices accompanying large reductions in generic prices as entry of generics occurs. Grabowski and Vernon [9] examined data on 18 major orally-administered drug products subject to generic competition between 1983 and 1987, and found that the name brand price increased by an average of $7 \%$ one year subsequent to generic entry and $11 \%$ two years following generic entry.

*This paper was presented at the OTA Sponsored Workshop on Government Policies and Pharmaceutical R\&D Methodology. This research was in part supported by a contract from the OTA of the U.S. Congress. We are grateful to Bill Comanor, Randy Ellis, Marty Gaynor, Alison Masson, Tom McGuire, Walt Salmon, Frederic Scherer, Judy Wagner and participants at the OTA Workshop, the BU-Harvard-MIT Health Economics Workshop, and a seminar at the Rand Corporation for comments and suggestions. 
The main goal of this paper is to examine how entry by generics can lead to price increases for brand name drugs. We take as a point of departure the observation made frequently by others that the demand side of the market for prescription drugs consists of two segments $[10 ; 28 ; 27$; 9]. One segment (consisting largely of hospitals, HMOs and Medicaid patients) is sensitive to differences between brand-name and generic prices, while the other (mainly comprised of individuals purchasing drugs in a retail outlet based on prescriptions from office-based physicians), is not sensitive to these price differences.' We examine models based on this characterization of demand to determine the circumstances under which price increases in response to market entry by generics will occur. ${ }^{2}$

A second facet of our analysis concerns the simultaneous response of brand-name advertising and brand-name price to generic entry. Since there is some evidence from two recent studies [10; 3] that advertising tends to fall with generic entry, we explore the conditions under which this can occur in tandem with a positive price response to entry.

The paper is organized into five sections. The next section presents a simple brand name pricing model based on market segmentation. In addition to describing the conditions under which generic entry increases brand-name price in this model, we also consider whether recent institutional trends in the health sector, which are changing the relative magnitudes of the two segments of market demand, will alter these condtions. The simple model is extended to incorporate advertising in the third section. The fourth section reviews recent empirical evidence of price increasing entry and advertising responses to entry. A final section offers conclusions and observations on future research and policy directions.

\section{A Simple Market Segmentation Model}

\section{Background}

We noted above that one could view the demand for brand-name prescription drugs as composed of two segments, one in which buyers are sensitive to prices of generic equivalents and one in which they are not. ${ }^{3}$ Recent developments in the health care sector have enlarged the cross-price sensitive segment of the market. Hospitals are increasingly being paid under reimbursement arrangements which create incentives to reduce the costs per admission [13; 18]. Foremost among these arrangements has been the introduction of the Medicare Prospective Payment System (PPS). The per case prospective payment approach to reimbursement, adopted under PPS, pays hospitals a fixed amount for each admission based in part on a patient's diagnosis. ${ }^{4}$ Thus the marginal revenues stemming from any treatment activities subsequent to admission are zero. This creates strong

1. Medicaid is a major purchaser of pharmaceutical products. A number of states will only reimburse sellers for the price of a generic product if one exists. Others deny reimbursement for costly drug products. The reimbursable products are listed in a state's Medicaid formulary.

2. Grabowski and Vernon [9] offer a specific example where a profit-maximizing firm would increase price in response to entry. Our purpose is to provide a more general characterization of the cases where this would be true.

3. There have been a number of models in the literature that are concerned with entry which leads to price increases in oligopolistic or monopolistically competitive markets $[17 ; 19 ; 20]$. These models generate price increases in response via one of two general mechanisms. The first is to assume economies of scale [19]. A second approach is for entry to both shift demand curves and to make them less elastic [17;20]. Our analysis takes the second general approach.

4. The PPS system bases its payments on the national historical average costs of care for patients falling into each of approximately 470 diagnostic clusters. In addition, hospitals may receive special adjustments to their payment rate based on whether they are teaching hospitals, serve disproportionate shares of indigent patients, etc. 
incentives for hospitals to be price sensitive in their input purchasing activities. Pharmaceuticals represent an important set of treatment inputs.

The new financial incentives appear to have altered the behavior of hospitals over time. Hospitals are increasingly adopting policies that are aimed at reducing pharmaceutical costs. Stolar [24] reports that from 1985 to 1987 the portion of hospitals with a policy of an automatic exchange of therapeutic alternatives, based on price, increased from $47.5 \%$ to $52.5 \%$. In addition, the percentage which placed restrictions on certain high cost drugs grew from $25.7 \%$ in 1985 to $27.7 \%$ in 1987 . These data suggest that a significant share of hospitals are making generic vs. brand name price comparisons in pharmaceutical purchasing, and that this share is growing over time.

A second part of the cross-price sensitive segment of the market for pharmaceuticals consists of Health Maintenance Organizations (HMOs). HMOs provide health care coverage and services for roughly $11 \%$ of the U.S. population [11]. They generally offer relatively extensive coverage for prescription pharmaceuticals [8]. Since HMOs receive a fixed payment for providing individuals with an agreed upon set of health care services (usually with little or no cost sharing), HMOs usually receive no marginal revenue associated with any services. The HMO's incentive is to treat each case as economically as possible. HMOs are therefore likely to be sensitive to generic vs. brand name price differences. This is supported by data from Weiner et al. [30] that on average $31 \%$ of all HMO pharmacy claims are for generics, while in insurance plans that cover fee-for-service medical practice the generic share of claims is only about $14 \% .^{5}$

A recent survey of HMOs ascertained the extent of therapeutic substitution of generic for brand name pharmaceuticals [5]. Approximately $31 \%$ of the surveyed HMOs used therapeutic substitution. Thirty-six percent of the HMOs that did not make use of therapeutic substitution refrained because it would violate state law.

Medicaid programs account for roughly $50 \%$ of third party payments for pharmaceutical products. State Medicaid programs have adopted several strategies for encouraging use of generic substitutes by beneficiaries [12]. One approach is to set reimbursement levels to pharmacists for drugs at the price of the generic products in the chemical class, if they exist. Another approach, used by one third of the states, is to define a set of drugs for which Medicaid will reimburse sellers. Some very costly drugs are excluded from this Medicaid formulary and are therefore not eligible for reimbursement [7].

\section{Assumptions}

Our analysis of brand name price responses to market entry begins by assuming that the brand name producer is a dominant firm that incorporates price responses of generics to its own pricing decisions while the generic producers are fringe firms that take the brand name price as given. (Thus, our model is a Stackelberg game.) Data on market shares of brand name and generic products are consistent with this characterization $[4 ; 10]$. The profit maximizing brand name producer is assumed to face a product market that is divided into two segments: loyal customers $\left(D_{L}\right)$ whose demand is unaffected by the price of generic substitutes and a cross-price-sensitive segment $\left(D_{S}\right)$ whose demand is influenced by both the brand name and generic prices [17].

Our one period model assumes that barriers to entry for generics are low, as is implied by

5. Research by Statman [23] and Bond and Lean [2] suggest that physicians have considerable loyalty to name brand drugs regardless of price. This is in part evidenced by very low rates of generic prescribing by office based physicians $[15 ; 10]$. 
the provisions of the Drug Price Competition and Patent Term Restoration Act of 1984 [28], and that the costs of changing both brand name and generic prices are low. This implies that future entry decisions will not be affected by the current brand name price. The brand name firm is assumed to be aware of this and hence sets price in each time period taking as exogenous the number of current and future generic producers, denoted by $n .{ }^{6}$ The generic market is characterized by a Nash equilibrium among the $n$ identical firms who take brand name price $\left(P_{b}\right)$ as given. ${ }^{7}$

\section{The Model}

The brand name producer's demand function is

$$
Q_{b}=D_{L}\left(P_{b}\right)+D_{S}\left(P_{b}, P_{g}\right)
$$

where $Q_{b}$ is the name brand quantity demanded, $P_{b}$ and $P_{g}$ are the brand name and generic prices respectively, and $D_{L}$ and $D_{S}$ represent the loyal and cross-price sensitive segments of the brand name firm's demand function. The market demand function for the $n$ identical generic producers is $D_{G}\left(P_{g}, P_{b}\right)$ and the equilbrium value of $P_{g}$ is $P_{g}^{*}\left(n, P_{b}\right){ }^{8}$ This is the profit maximizing value of $P_{g}$ in a Nash non-cooperative game. Substituting the expression for $P_{g}^{*}$ into equation (1), and denoting the brand name producer's cost function by $C\left(Q_{b}\right)$, we write the brand name firm's profit function as

$$
\begin{aligned}
\pi= & P_{b}\left\{D_{L}\left(P_{b}\right)+D_{s}\left[\left(P_{b}, P_{g}^{*}\left(n, P_{b}\right)\right]\right\}\right. \\
& C\left\{D_{L}\left(P_{b}\right)+D_{S}\left[P_{b}, P_{g}^{*}\left(n, P_{b}\right)\right]\right\} .
\end{aligned}
$$

Maximization of profit with respect to own price $\left(P_{b}\right)$ yields the first order condition

$$
\begin{aligned}
d \pi / d P_{b}=0= & {\left[d D_{L} / d P_{b}+\partial D_{S} / \partial P_{b}+\left(\partial D_{S} / \partial P_{g}\right)\left(\partial P_{g}^{*} / \partial P_{b}\right)\right] } \\
& \left(P_{b}-\left(d C / d Q_{b}\right)\right)+D_{L}\left(P_{b}\right)+D_{S}\left[P_{b}, P_{g}^{*}\left(n, P_{b}\right)\right] .
\end{aligned}
$$

Note that the first term of (3), which summarizes the demand response to a change in $P_{b}$, must be negative for the first order condition to hold. The demand response consists of the direct effects on the two segments of the demand function plus an indirect effect which works through the price reaction function that is determined in the sub-market for generics. For given values of $n$, $D_{L}\left(P_{b}\right)+D_{s}\left[P_{b}, P_{g}^{*}\left(n, P_{b}\right)\right]$ can be viewed as the reduced-form demand curve for the brand-name firm. Equation (3) requires that this reduced-form demand curve be negatively sloped. ${ }^{9}$

6. Thus, we exclude the possibility of "limit price" behavior. Tirole [25] points out that limit pricing is unlikely under the assumptions we have outlined. He notes that incumbent (brand-name) price may be correlated with productive capacity commitment; however, capacity constraints are probably not an important consideration in producing pharmaceuticals (though they may become more important in the market for biologically-produced products). Moreover, the Milgrom-Roberts [16] explanation of limit pricing where incumbent price is an imperfect signal of incumbent cost is also of limited relevance in the pharmaceutical context where production costs are small relative to prices and relative to total firm expenditures on drug development, production, marketing and distribution.

7. In order to examine the sensitivity of our results to the assumption that the generic price is endogenous to the brand-name firm, we also examined a Bertrand model in which this firm takes generic price as exogenous. The analytical results closely parallel the findings reported here.

8. The relationship between $P_{g}^{*}$ and $n$ can also be derived from more general models where $n$ identical firms have non-zero conjectural variations with respect to each other's output. See for example Waterston [29].

9. If $\partial P_{g} / \partial P_{b}>0$, the reduced form demand curve will be less own-price elastic than the ordinary demand curve for the brand name drug. 
The effect of entry by generics on name brand price can be assessed by total differentiation of equation (3) to obtain an expression for $d P_{b} / d n$. Using this expression, we examine the conditions under which market entry will increase name brand price $\left(d P_{b} / d n>0\right)$. (Algebraic detail is supplied in the appendix).

We can express $d P_{b} / d n$ as:

$$
\begin{aligned}
d P_{b} / d n= & \left\{( P _ { b } - ( d C / d Q _ { b } ) ) \left[\left(\partial^{2} D_{S} / \partial P_{b} \partial P_{g}\right)\left(\partial P_{g}^{*} / \partial n\right)+\right.\right. \\
& \left.\left.\left(\partial^{2} D_{S} / \partial P_{g}^{2}\right)\left(\partial P_{g}^{*} / \partial n\right)\left(\partial P_{g}^{*} / \partial P_{b}\right)+\left(\partial D_{S} / \partial P_{g}\right)\left(\partial^{2} P_{g}^{*} / \partial P_{b} \partial n\right)\right]\right\} /-S O C+ \\
& \left\{\left(\partial D_{S} / \partial P_{g}\right)\left(\partial P_{g}^{*} / \partial n\right)\right\} /-S O C-\left\{\left(d^{2} C / d Q_{b}^{2}\right)\left[\left(\partial D_{S} / \partial P_{g}\right)\left(\partial P_{g}^{*} / \partial n\right)\right]\right. \\
& {\left.\left[d D_{L} / d P_{b}+\partial D_{S} / \partial P_{b}+\left(\partial D_{S} / \partial P_{g}\right)\left(\partial P_{g}^{*} / \partial P_{b}\right)\right]\right\} /-S O C, }
\end{aligned}
$$

where $S O C$ is the right-hand-side (r.h.s.) of the second-order condition (A1 in the appendix) and must be negative. With $\partial D_{S} / \partial P_{g}>0$ and $\partial P_{g}^{*} / \partial n<0$, the second right-hand term in (4) must be negative. The third right-hand term must also be non-positive, since the reduced-form demand curve slopes downward, unless there are decreasing marginal costs for the brand-name firm. The first bracketed term on the right hand side of (4) is the mark-up of name brand price over marginal cost (which must be positive). The second bracketed term is the effect of generic entry on the slope of the reduced form demand curve. The sign of this term is difficult to determine a priori. The slope of the price-sensitive portion of the reduced-form demand curve summarizes heterogenous responses of individual cross-price sensitive buyers to price increases which may be of two types: reducing the quantity purchased to some non-zero amount and reducing purchases to zero. The reduction in $P_{g}^{*}$ as $n$ increases could affect this slope by affecting either or both types of responses. If for example, the purchasers with the strongest own-price response are more likely to reduce their purchases to zero as $P_{g}^{*}$ falls, this will result in a steeper slope for the reduced-form demand curve since the remaining cross-price sensitive purchasers have (by assumption) weaker price responses.

Equation (4) shows that $d P_{b} / d n$ can not be positive unless either 1) entry increases the demand for the brand name drug, 2) marginal costs are decreasing for the brand-name product or 3 ) entry makes the reduced-form demand curve steeper (less elastic). Of course, the first of these possibilities seems rather implausible since it would require that generic prices rise with entry or that brand-name demand falls when generic prices rise (implying that the products are gross complements in demand). The empirical evidence of the impact on demand suggests at least small reductions in brand name market shares following market entry [23]. Little systematic empirical work on the nature of returns to scale has been reported in the literature. There is, however, little reason to believe that the marginal production costs of a specific drug would be decreasing, nor has this claim appeared in industry studies [4]. This leaves the third possibility, that entry makes the reduced-form demand curve steeper, as the most plausible explanation for $d P_{b} / d n>0$.

\section{Variations in Market Shares of Loyal and Cross-Price-Sensitive Consumers}

We have already cited evidence pertaining to HMO's, hospital purchasing practices, and Medicaid which suggests that the relative market share of price-sensitive consumers has been increasing. We now consider the implications of this trend for brand-name prices and for the responses of these prices to generic entry. We begin by reformulating the brand-name demand function in equation (1) as a weighted sum

$$
Q_{b}=(1-\alpha) D_{L}\left(P_{b}\right)+\alpha D_{S}\left(P_{b}\right)
$$


where $\alpha$ is the weight of price-sensitive consumers in the market. The first-order condition for profit maximization now becomes

$$
\begin{aligned}
d \pi / d P_{b}=0= & {\left[(1-\alpha)\left(d D_{L} / d P_{b}\right)+\alpha\left(\partial D_{S} / \partial P_{b}+\left(\partial D_{S} / \partial P_{g}\right)\left(\partial P_{g}^{*} / \partial P_{b}\right)\right)\right] } \\
& \left(P_{b}-d C / d Q_{b}\right)+(1-\alpha) D_{L}\left(P_{b}\right)+\alpha D_{S}\left[P_{b}, P_{g}^{*}\left(n, P_{b}\right)\right] .
\end{aligned}
$$

The effect of a change in $\alpha$ on the profit-maximizing level of $P_{b}$ is

$$
\begin{aligned}
d P_{b} / d \alpha= & \left\{\left[-d D_{L} / d P_{b}+\partial D_{S} / \partial P_{b}+\left(\partial D_{S} / \partial P_{g}\right)\left(\partial P_{g}^{*} / \partial P_{b}\right)\right] .\right. \\
& \left.\left(P_{b}-\left(d C / d Q_{b}\right)\right)-D_{L}\left(P_{b}\right)+D_{S}\left[P_{b}, P_{g}^{*}\left(n, P_{b}\right)\right]\right\} /-S O C .
\end{aligned}
$$

Note that the numerator of the first r.h.s. term in (5) is proportional to the difference in own-price response of the loyal and cross-price-sensitive reduced-form demand curves while the numerator of the second r.h.s. term is the difference in quantity demanded between the loyal and cross-pricesensitive portions of the market. If one assumes that the shift of a purchaser from the former to the latter portion (which causes an increase in $\alpha$ ) does not affect the quantity demanded for that purchaser (given prevailing levels of $P_{b}$ and $P_{g}$ ), the second r.h.s. term vanishes. The first r.h.s. term will be negative (positive) if the own-price response of the cross-price sensitive demand is greater (lesser) than that of the loyal purchasers. While this might seem plausible, it is not obviously so; in particular, one might expect the response of reduced-form demand to be smaller for the cross-price sensitive purchasers if $\partial P_{g}^{*} / \partial P_{b}$ is strongly positive.

It is also interesting to consider the effect of changes in $\alpha$ on the response of $P_{b}$ to entry. Grabowski and Vernon [9] noted that brand-name price declines in response to entry were more commonly observed for injectable products that are purchased primarily by cross-price-sensitive hospitals. They went on to speculate that in the market for the orally-administered pharmaceuticals which they studied, the effect of expanding the cross-price-sensitive portion of the market (i.e., an increase in $\alpha$ ) would be to make $d P_{b} / d n$ more negative. To examine their conjecture explicitly, the relevant expression to evaluate is

$$
d\left(d P_{b} / d n\right) / d \alpha=\partial\left(d P_{b} / d n\right) / \partial \alpha+\left(\partial\left(d P_{b} / d n\right) / \partial P_{b}\right)\left(P_{b} / d \alpha\right)
$$

In the simple linear case where $D_{L}=a_{L}-b_{L} P_{b}, D_{S}=a_{S}-b_{S} P_{b}-v n+z P_{b} n$, and marginal cost $=$ average cost $=$ the constant $m$, (6) becomes

$$
\begin{aligned}
d\left(d P_{b} / d n\right) / d \alpha= & \left\{S O C \cdot\left(v-z\left(2 P_{b}-m\right)\right)-2 \alpha \cdot\left(v-z\left(2 P_{b}-m\right)\right) \cdot\left(b_{L}-b_{S}+z n\right)+\right. \\
& \left.2 \alpha z \cdot\left(P_{b}-m\right)\left(b_{L}-b_{S}+z n\right)+Q_{S}-Q_{L}\right\} / S O C^{2} .
\end{aligned}
$$

Notice that the term $\left(v-z\left(2 P_{b}-m\right)\right)$ will be negative if $d P_{b} / d n>0$. In this case, since $S O C<0$, sufficient conditions for the validity of the Grabowski-Vernon conjecture are that $\left(b_{L}-b_{S}+z n\right)<0$ and $\left(Q_{S}-Q_{L}\right) \leq 0$. On the other hand, as noted above, the difference in own-price responses of the two demand functions, which here equals $\left(b_{L}-b_{S}+z n\right)$, may not be negative, particularly if $\partial P_{g}^{*} / \partial P_{b}$ is strongly positive. Thus, while our analysis does not controvert the Grabowski-Vernon conjecture, it does point out that there are plausible cases where it does not hold. Finally, note that the same factors which imply a less positive brand-name price response to entry as $\alpha$ increases (i.e., $Q_{S}-Q_{L}<0$ and $\left.\left(b_{L}-b_{S}+z n\right)<0\right)$ also imply that $d P_{b} / d \alpha<0$. 


\section{Advertising: Extending the Basic Model}

There has been a substantial amount of research on the impact of advertising (or promotion) on competition and innovation in the market for pharmaceuticals [4]. Far less attention appears to have been devoted to the impact of generic entry on brand-name advertising. Since there is empirical evidence (discussed below) that generic entry reduces brand-name advertising, we focus our analysis on exploring the conditions under which this decline in advertising would occur simultaneously with a rise in brand-name price.

Several competitive roles for the influence of advertising on competition have been proposed in the literature. Leffler [14] describes informational advertising which serves to improve consumer knowledge. The effect of informational advertising for a name brand firm may be to increase aggregate demand for a class of pharmaceuticals, or to increase its own demand if there exist true quality differentials that can be publicized. Persuasive advertising constitutes a second class of promotional activity. This form of advertising is posited to make firm demand curves less price elastic.

Comanor [4] suggested that name brand firms may use advertising to "jam" the informational signal sent by generic entrants thereby reducing the "effective" information received about competitors. Schmalensee [21] has developed a general model where advertising serves to reinforce existing brand loyalties, which results in name brand demand curves becoming less price elastic. Still others have suggested that advertising raises the costs of entry thereby reducing potential price competitors [22].

We expand our basic model by adding expenditures on advertising, $A$, as a second decision variable for the brand name firm. By adding $A$ as an argument in the $D_{L}, D_{S}$, and $P_{g}^{*}$ functions the first order condition given in (3) becomes

$$
\begin{aligned}
\partial \pi / \partial P_{b}=0= & {\left[\partial D_{L} / \partial P_{b}+\partial D_{S} / \partial P_{b}+\left(\partial D_{S} / \partial P_{g}\right)\left(\partial P_{g}^{*} / \partial P_{b}\right)\right] \cdot } \\
& {\left[P_{b}-d C / d Q_{b}\right]+D_{L}(\cdot)+D_{S}(\cdot) } \\
\partial \pi / \partial A=0= & {\left[\partial D_{L} / \partial A+\partial D_{S} / \partial A+\left(\partial D_{S} / \partial P_{g}\right)\left(\partial P_{g}^{*} / \partial A\right)\right]\left[P_{b}-\left(d C / d Q_{b}\right)\right]-1 . }
\end{aligned}
$$

Equation (3b) is identical to (3) above. Equation (3c) states that at the optimum, a brand name firm will expand advertising expenditures up to the point where the additional sales revenue minus production cost generated by the marginal dollar of advertising expenditure is unity. (Equations (3b) and (3c) correspond to the standard Dorfman-Steiner [6] result.) By totally differentiating (3b) and (3c) and allowing $n, A, P_{b}$, and $P_{g}$ to vary we can derive expressions for $d P_{b} / d n$ and $d A / d n$. Detailed derivations of these expressions are presented in the appendix.

Under the maintained assumption of constant marginal costs, sufficient conditions in this model for predicting $d P_{b} / d n>0$ and $d A / d n<0$ are the following:(1) entry makes the reducedform brand-name demand curve substantially steeper, (2) advertising has a negative effect on the (negative) reduced-form demand response to entry, and (3) advertising makes the reduced-form demand curve substantially flatter. The mathematical statement of these conditions (given in the appendix) is that (1) $n^{a}>0$, (2) $n^{b}<0$ and (3) $A^{a}<0$. (See the discussion in the appendix and equations (A4), (A5), and (A7)-(A9) for definitions of these terms.) Condition (1) is the same condition required for a positive brand-name price response to entry in the basic model (section II above). Conditions 2 and 3 seem likely to be met if brand-name advertising is market expanding, that is, if it increases the number of persons using a drug or increases the uses to which the drug is put. In this case, the reduction in quantity demanded as entry occurs (and $P_{g}$ falls) should also be 
larger. Advertising could, however, have the opposite result. If brand-name advertising focuses primarily on differentiating brand-name from generic products, it may diminish the cross-price sensitivity of brand-name demand and thereby reduce the size of the (negative) demand response to entry. Finally, note that our model does not generate qualitative predictions about the signs of $d P_{b} / d n$ and $d A / d n$ in a number of other cases (see Appendix Table I). These cases could also be consistent with the observed empirical evidence of simultaneous brand-name price increases and advertising decreases in response to entry.

\section{Empirical Evidence on Pricing, Advertising and Patent Expiration}

There are three studies which directly estimate impacts of market entry on name brand prices. Two of the studies make use of data which reflect pricing behavior during the period subsequent to the Drug Act of $1984[9 ; 3]$.

The earliest study which is relevant to the models developed above is that by Statman [23]. In that work the pricing behavior of 12 name brand drugs was examined before and after expiration of their patents. The analysis focused on prices and purchases by drug stores. The empirical estimates of price response and market share changes indicated little change in either. On average market share fell to $96 \%$ of its initial level. Only one of the 12 brand name prices fell significantly following patent expiration. This evidence does not support the proposition that prices will increase following patent expiration. The very small market share changes suggest very low generic-price elasticity of brand-name demand; thus, the entry-induced shift in the slope of the brand-name reduced form demand curve may not have been sufficient to create the types of responses outlined above. ${ }^{10}$

Grabowski and Vernon [9] studied the effect of generic entry on prices for 18 high sales volume pharmaceutical products that were first exposed to generic competition during the years 1983 through 1987. For each drug the authors examined prices prior to entry and prices 1 year subsequent to generic entry. Using a rather sparse regression model they estimated the impact of the number of generic suppliers in a market on the ratio of the generic price to the name brand price. " The estimated coefficient for the effect of the number of generics on the ratio of generic to name brand price is negative and significant at conventional levels. This result is consistent with the descriptive statistics presented by Grabowski and Vernon [9] showing that name brand prices rose relative to generic prices subsequent to generic entry.

In an interesting and comprehensive study of generic entry effects on markets for brand-

10. Earlier studies of drug pricing by Schwartzman [22] and Weston [31] found little evidence of brand-name price responses to entry outside the market for anti-infectives. Moreover, the estimates produced by those studies are somewhat difficult to interpret. Since only simple regression models were estimated, it is not possible to disentangle the impacts of increased competition in a therapeutic market from the aging of particular pharmaceutical products. Most other studies have focused on entry by new drugs into a therapeutic class. That situation is somewhat different from the one examined in the theoretical work above. Some results from those studies are informative for the analysis of patent loss and price competition. The study by Bond and Lean [2] found that physician prescribing practices were quite unresponsive to newly entering drugs that offer little or no therapeutic gain over the original product. This is not necessarily informative because in our model we view demand stemming from office based physician contacts as falling into the "loyal" market segment; the effect of entry on the price responsive segment of the market is the critical factor in explaining post-entry brand-name price increases.

11. The regression included two covariates along with the number of generics. They were: (1) the total dollar sales in a market in a given year and (2) a time dummy. 
name drugs, Caves, Whinston and Hurwitz [3] suggest that simple pre-entry versus post-entry brand-name price comparisons or regressions of price on numbers of generic entrants may understate negative entry effects on prices because other omitted factors have caused brand-name prices to rise over time. In particular, they observe that after 1982 the Producer Price Index (PPI) for pharmaceuticals rose sharply relative to indices of labor and material input costs. Lacking observable variables which can explain this deviation from historical patterns, they argue that empirical price regression models must be specified so as to minimize bias from the unobservable, time-varying factors which have produced this result. ${ }^{12}$

In their own empirical analyses of brand-name prices, Caves, Whinston and Hurwitz examine the experience of 30 drugs in seven therapeutic categories that went off patent during the period 1976 through 1987. These drugs represented all drugs in therapeutic classes where "important" drugs had lost their patents for which data on patent expiration dates were precise. In their regression model of the impact of generic entry on brand-name prices, more than fifty individual intercepts were included for each of the year-therapeutic category combinations in their data. (This necessitated dropping two of the 30 drugs which were the only ones in their therapeutic categories.) Their regression results therefore represent an analysis of deviations in individual drug price changes from the therapeutic category-year group average changes in each year. In addition, a number of other time-related dummy variables, linear time trends and quadratic time trends were included to capture presumed discontinuities in behavior around the initial year on the market, the years before and after patent expiration and product life-cycle effects.

The measure of entry used was the number of Amended New Drug Applications for marketing of a particular chemical entity; actual entry was not directly measured. The estimated regressions indicated that the initial entry of generics led to reductions in name brand price of roughly $2 \%$. Entry by 20 generics resulted in estimated name brand price reductions of $17 \%$. These were viewed as small price responses to entry. Analyses that allowed for different price responses to entry depending on the importance of hospital purchasers indicated more negative price responses to entry when the hospital market share was larger. In view of the very complicated structure of additional time-related variables in the model, however, it would be important to know the sensitivity of these results to the precise specification chosen by the authors.

Caves, Whinston and Hurwitz [3] also estimated a regression model for the ratio of generic to brand-name prices similar to that estimated by Grabowski and Vernon [9]. Their only explanatory variables were the number of generic entrants and the square of this number. Individual intercepts were included for each drug but no time-related or year-related dummies were included. Their results paralleled Grabowski and Vernon [9] in that increasing the number of generic entrants had a strong downward effect on generic prices relative to brand-name prices; in particular, the generic-brand name price ratio was estimated to fall from 0.599 to 0.201 as the number of entrants increased from one to 20 .

Several recent empirical studies have reported the result that generic entry reduces brandname advertising. Hurwitz and Caves [10] examined the relationship between promotional activities, especially advertising, and market shares using data on 150 drug products for the years 1978 to 1983. The econometric model of advertising and market share yielded estimates of the impact

12. It should be noted that Berndt, Griliches and Rosett [1] have argued that rates of increase in the PPI data for drugs over the recent past have been biased upward by a substantial amount. Their analysis shows that one reason for this bias is the difference in price behavior between the drug products included in the PPI sample and the universe of drug products. 
of number of sellers on the advertising effort of the leading firm (as measured by the advertising to sales ratio and total promotional outlays). The results indicate a negative relationship between the number of firms in the market and both measures of advertising. ${ }^{13}$

Caves, Whinston and Hurwitz [3] modeled the response of advertising expenditures to entry of generic competitors for 25 drugs that (1) went off patent during the period 1976-1987 and (2) reported more than 80 per cent of their sales revenues from non-hospital pharmacies. Advertising expenditures were regressed on explanatory variables relating to the years after first sale of the brand-name drug (to capture product life-cycle effects), number of approved generic equivalent drugs (their measure of entry), dummy variables for the two years before patent expiration and the year after patent expiration, and a variable measuring years since patent expiration. Their results indicated strong negative effects of entry on advertising with the first approved generic producing a fall of 20 per cent and additional entrants up to ten producing additional declines of 60 per cent. ${ }^{14}$

In summary, the results from the three most relevant empirical studies of brand name pricing are decidedly mixed. The descriptive evidence strongly suggests price increases following entry $[9 ; 28]$. The multivariate analyses are less clear on the point. This may in part result from data limitations that hinder the ability to hold constant many relevant factors [9]. None of the studies suggests strong name brand price reductions in response to generic entry. The empirical results for the impact of generic entry on advertising $[10 ; 3]$ are more consistent in pointing to a strong post-entry decline in advertising, but the number of studies dealing with this issue is still small.

\section{Concluding Remarks}

The models we have developed above show that price increases in name brand pharmaceutical products stemming from market entry due to patent loss may be explained by optimizing behavior by the name brand producer. On the assumption that marginal drug production costs are approximately constant, analysis of our basic model indicates that a necessary condition for such price increases is that entry leads to a decline in the own-price elasticity of reduced-form brand-name demand. Analysis of a model incorporating advertising shows that with constant marginal costs, sufficient conditions for simultaneous brand-name price-increases and advertising decreases in response to entry are that

(1) entry leads to a substantial decline in the own-price elasticity of reduced-form brandname demand;

(2) increased advertising leads to a substantial decrease in the slope of the reduced-form brand-name demand curve; and

(3) advertising has a negative effect on the (negative) reduced-form demand response to entry.

13. The estimate for effect of the number of sellers on the advertising to sales ratio was negative with a $t$ statistic of 1.62 which is significant at the 0.10 level using a two tailed test. The result for total promotional outlays by the leading firm was also negative but no standard error or $t$ statistic was reported (see footnote \#42 in Hurwitz and Caves [10]).

14. Caves, Whinston and Hurwitz [3] view their finding of a negative $d A / d n$ as supporting the view that "expanding the overall market for the chemical entity is a significant function of branded-drug advertising." Of course, the analysis in our appendix shows that the sign of $d A / d n$ depends upon a number of different factors in addition to the effect of advertising on the level of demand. Our overall analysis, however, supports this intuition of Caves, Whinston and Hurwitz [3] about the nature of advertising. 
We also note that advertising which is market-expanding is most likely to be consistent with conditions (2) and (3). More generally, our analysis shows that the observed patterns of entry effects on prices and advertising can be explained by the properties of the reduced-form brand-name demand function and the nature of brand-name advertising.

Our analysis also examined the implications, for brand-name prices and entry effects on these prices, of relative growth in the cross-price-sensitive share of the demand side of the pharmaceutical market. The principal conclusion was that this relative growth would tend to reduce prices and increase the downward pressure of entry on prices if (1) the process causing this relative growth did not increase the overall level of brand-name demand and (2) the reduced-form demand curve for cross-price-sensitive buyers was more own-price elastic than was the demand curve for other ("loyal") buyers.

One outcome that is consistent with our model and supported by descriptive statistics is that brand-name price rises while the average price (including both brand-name and generic products) of a prescription falls. This would mean that the Drug Price Competition and Patent Restoration Act of 1984 would be having its desired effect. Moreover, our results at least point to the possibility that name-brand price increases in response to entry will be attenuated as the cross-price-sensitive segment of the market continues to expand.

Future researchers may wish to explore the use of more sophisticated models to probe further the implications of patent loss and entry. One direction for extending this analysis is to incorporate intertemporal demand considerations such as durability of advertising effects [3]. Grabowski and Vernon [9] have also suggested extending the model to allow for brand-name price effects on entry; to do so, however, one would need to formulate convincing a priori arguments for limit pricing behavior.

Further empirical research on the structural relationships of our models would also be valuable. Based on our analysis, research on demand for brand-name drugs should focus on the effect of generic prices on own-price demand elasticity for name brands and the effect of advertising on own-price and cross-price elasticities. We are unaware of direct empirical estimates for these factors in the literature. Empirical estimates of the generic price function, $P_{g}^{*}\left(P_{b}, A, n\right)$, are also needed..$^{15}$

Another worthwhile direction for future empirical research is to develop separate estimates of demand functions for "loyal" and cross-price-sensitive buyers. From a policy perspective, this research would have considerable interest. With the growing cost-consciousness of hospitals, Medicaid programs, HMOs, and other private insurance arrangements, it is important to know the implications of this trend for prices, for drug expenditures under public and private insurance programs, and for the power of generic entry to generate competitive pressures on brand-name prices.

Finally, as Caves, Whinston and Hurwitz [3] have noted, a more complete understanding of the implications of patent policy obviously requires further research on the entry process itself. In the only econometric analysis of recent data of which we are aware, Grabowski and Vernon [9] have estimated a generic entry model and reported that the brand-name price-cost margin at the time of the first generic entry is the most important determinant of the number of generic entrants. In view of concerns about limit pricing models expressed above, the reasons for this connection between mark-ups and entry are an obvious subject for further inquiry.

15. The relative price regressions estimated by Grabowski and Vernon [9] and Caves, Whinston and Hurwitz [3] might be viewed as approximations to the $P_{g}^{*}(\cdot)$ function with the elasticity of $P_{g}^{*}$ with respect to $P_{b}$ constrained to 1 . Neither of these studies estimates advertising effects on $P_{g}^{*}$ or unrestricted coefficients for $P_{b}$. Grabowski and Vernon [9] also include a sales volume variable, which might pose endogeneity problems. 


\section{Appendix: Comparative Statics Analysis of Entry Effects on Brand-Name Prices}

\section{Basic Model}

We begin by noting that the second-order maximization condition corresponding to equation (3) in the text is:

$$
\begin{aligned}
0> & \left(2-\left(d^{2} C / d Q_{b}^{2}\right)\left[d D_{L} / d P_{b}+\partial D_{S} / \partial P_{b}+\left(\partial D_{S} / \partial P_{g}\right)\left(\partial P_{g}^{*} / \partial P_{b}\right)\right]\right) \\
& {\left[d D_{L} / d P_{b}+\partial D_{S} / \partial P_{b}+\left(\partial D_{S} / \partial P_{g}\right)\left(\partial P_{g}^{*} / \partial P_{b}\right)\right]+} \\
& {\left[P_{b}-\left(d C / d Q_{b}\right)\right]\left[d^{2} D_{L} / d P_{b}^{2}+\partial^{2} D_{S} / \partial P_{b}^{2}+2\left(\partial^{2} D_{S} / \partial P_{b} \partial P_{g}\right)\left(\partial P_{g}^{*} / \partial P_{b}\right)+\right.} \\
& \left.\left(\partial^{2} D_{S} / \partial P_{g}^{2}\right)\left(\partial P_{g}^{*} / \partial P_{b}\right)^{2}+\left(\partial D_{S} / \partial P_{b}\right)\left(\partial^{2} P_{g}^{*} / \partial P_{b}^{2}\right)\right]
\end{aligned}
$$

Denoting the right-hand side of this inequality by $S O C$, we obtain the following equation by total differentiation of equation (3) in the text, allowing $n, P_{b}$, and $P_{g}^{*}$ to vary:

$$
\begin{aligned}
0= & d P_{b} \cdot S O C+d n\left(P_{b}-\left(d C / d Q_{b}\right)\right)\left(\left(\partial^{2} D_{S} / \partial P_{b} \partial P_{g}\right)\left(\partial P_{g}^{*} / \partial n\right)+\right. \\
& \left.\left(\partial^{2} D_{S} / \partial P_{g}^{2}\right)\left(\partial P_{g}^{*} / \partial n\right)\left(\partial P_{g}^{*} / \partial P_{b}\right)+\left(\partial D_{S} / \partial P_{g}\right)\left(\partial^{2} P_{g}^{*} / \partial P_{b} \partial n\right)\right)+ \\
& d n\left(\partial D_{S} / \partial P_{g}\right)\left(\partial P_{g}^{*} / \partial n\right)- \\
& \left(d n\left(d^{2} C / d Q_{b}^{2}\right)\left(\partial D_{S} / \partial P_{g}\right)\left(\partial P_{g}^{*} / \partial n\right)\right) \cdot \\
& \left.\left(d D_{L} / d P_{b}+\partial D_{S} / \partial P_{b}\right)+\left(\partial D_{S} / \partial P_{g}\right)\left(\partial P_{g}^{*} / \partial P_{b}\right)\right)
\end{aligned}
$$

Rearranging the terms in (A2) yields equation (4) in the text.

\section{Advertising Model}

To facilitate the explanation of the comparative statics analysis in equations (3b) and (3c), we begin by defining and interpreting several expressions. Let

$$
\begin{aligned}
{\left[P^{a}\right] \equiv } & \left(2-\left(d^{2} C / d Q_{b}^{2}\right)\left[\partial D_{L} / \partial P_{b}+\partial D_{S} / \partial P_{b}+\left(\partial D_{S} / \partial P_{g}\right)\left(\partial P_{g}^{*} / \partial P_{b}\right)\right]\right) \\
& {\left[\partial D_{L} / \partial P_{b}+\partial D_{S} / \partial P_{b}+\left(\partial D_{S} / \partial P_{g}\right)\left(\partial P_{g}^{*} / \partial P_{b}\right)\right]+\left[P_{b}-\left(d C / d Q_{b}\right)\right] } \\
& {\left[\partial^{2} D_{L} / \partial P_{b}^{2}+\partial^{2} D_{S} / \partial P_{b}^{2}+2\left(\partial^{2} D_{S} / \partial P_{b} \partial P_{g}\right)\left(\partial P_{g}^{*} / \partial P_{b}\right)+\right.} \\
& \left.\left(\partial^{2} D_{S} / \partial P_{g}^{2}\right)\left(\partial P_{g}^{*} / \partial P_{b}\right)^{2}+\left(\partial D_{S} / \partial P_{g}\right)\left(\partial^{2} P_{g}^{*} / \partial P_{b}^{2}\right)\right]
\end{aligned}
$$

and let

$$
\begin{aligned}
{\left[n^{a}\right] \equiv } & \left(P_{b}-\left(d C / d Q_{b}\right)\right)\left(\left(\partial^{2} D_{S} / \partial P_{b} \partial P_{g}\right)\left(\partial P_{g}^{*} / \partial n\right)+\right. \\
& \left.\left(\partial^{2} D_{S} / \partial P_{g}^{2}\right)\left(\partial P_{g}^{*} / \partial n\right)\left(\partial P_{g}^{*} / \partial P_{b}\right)+\left(\partial D_{S} / \partial P_{g}\right)\left(\partial^{2} P_{g}^{*} / \partial P_{b} \partial n\right)\right)+ \\
& \left(\partial D_{S} / \partial P_{g}\right)\left(\partial P_{g}^{*} / \partial n\right)-d^{2} C / d Q_{b}^{2}\left(\left(\partial D_{S} / \partial P_{g}\right)\left(\partial P_{g}^{*} / \partial n\right)\right) \\
& \left.\left(\partial D_{L} / \partial P_{b}\right)+\left(\partial D_{S} / \partial P_{b}\right)+\left(\partial D_{S} / \partial P_{g}\right)\left(\partial P_{g}^{*} / \partial P_{b}\right)\right)
\end{aligned}
$$

Note that $\left[P^{a}\right]<0$ from the second-order conditions and that $\left[n^{a}\right]$ is equivalent to the numerator of equation (4) in the simple model. Let

$$
\begin{aligned}
{\left[A^{a}\right] \equiv } & \left(1-\left(d^{2} C / d Q_{b}^{2}\right)\left[\partial D_{L} / \partial P_{b}+\partial D_{S} / \partial P_{b}+\left(\partial D_{S} / \partial P_{g}\right)\left(\partial P_{g}^{*} / \partial P_{b}\right)\right]\right) \\
& {\left[\partial D_{L} / \partial A+\partial D_{S} / \partial A+\left(\partial D_{S} / \partial P_{g}\right)\left(\partial P_{g}^{*} / \partial A\right)\right]+\left[P_{b}-\left(d C / d Q_{b}\right)\right] } \\
& {\left[\partial^{2} D_{L} / \partial P_{b} \partial A+\partial^{2} D_{S} / \partial P_{b} \partial A+\left(\partial^{2} D_{S} / \partial P_{b} \partial P_{g}\right)\left(\partial P_{g}^{*} / \partial A\right)+\right.}
\end{aligned}
$$


Appendix Table I: Comparative Statics Results for Advertising Model

\begin{tabular}{|c|c|c|c|c|c|}
\hline \multirow[b]{2}{*}{ Case } & \multicolumn{3}{|c|}{ Assumed Sign of: } & \multicolumn{2}{|c|}{ Implied Sign of: } \\
\hline & $n^{a}$ & $n^{b}$ & $A^{a}$ & $d P_{b} / d n$ & $d A / d n$ \\
\hline 1 & + & + & + & + & + \\
\hline 2 & - & + & + & $?$ & $?$ \\
\hline 3 & + & - & + & $?$ & $?$ \\
\hline 4 & - & - & + & - & - \\
\hline 5 & + & + & - & $?$ & $?$ \\
\hline 6 & + & - & - & + & - \\
\hline 7 & - & + & - & - & + \\
\hline 8 & - & - & - & $?$ & $?$ \\
\hline
\end{tabular}

$$
\begin{aligned}
& \left(\partial^{2} D_{S} / \partial P_{g} \partial A\right)\left(\partial P_{g}^{*} / \partial P_{b}\right)+\left(\partial^{2} D_{S} / \partial P_{g}^{2}\right)\left(\partial P_{g}^{*} / \partial A\right)\left(\partial P_{g}^{*} / \partial P_{b}\right)+ \\
& \left.\left(\partial D_{S} / \partial P_{g}\right)\left(\partial^{2} P_{g}^{*} / \partial P_{b} \partial A\right)\right] ;
\end{aligned}
$$

note that the last bracketed term in (A5) is the effect of advertising on the slope of the reduced-form demand curve. We also define

$$
\begin{aligned}
{\left[A^{b}\right] \equiv } & -d^{2} C / d Q_{b}^{2}\left[\partial D_{L} / \partial A+\partial D_{S} / \partial A+\left(\partial D_{S} / \partial P_{g}\right)\left(\partial P_{g}^{*} / \partial A\right)\right]^{2}+ \\
& {\left[P_{b}-\left(d C / d Q_{b}\right)\right]\left[\partial^{2} D_{L} / \partial A^{2}+\partial^{2} D_{S} / \partial A^{2}+2\left(\partial^{2} D_{S} / \partial A \partial P_{g}\right)\left(\partial P_{g}^{*} / \partial A\right)+\right.} \\
& \left.\left(\partial^{2} D_{S} / \partial P_{g}^{2}\right)\left(\partial P_{g}^{*} / \partial A\right)^{2}+\left(\partial D_{S} / \partial P_{g}\right)\left(\partial^{2} P_{g}^{*} / \partial A^{2}\right)\right]
\end{aligned}
$$

and

$$
\begin{aligned}
{\left[n^{b}\right] \equiv } & \left(P_{b}-\left(d C / d Q_{b}\right)\right)\left(\left(\partial^{2} D_{S} / \partial A \partial P_{g}\right)\left(\partial P_{g}^{*} / \partial n\right)+\right. \\
& \left(\partial^{2} D_{S} / \partial P_{g}^{2}\right)\left(\partial P_{g}^{*} / \partial n\right)\left(\partial P_{g}^{*} / \partial A\right)+ \\
& \left.\left(\partial D_{S} / \partial P_{g}\right)\left(\partial^{2} P_{g}^{*} / \partial A \partial n\right)\right)-d^{2} C / d Q_{b}^{2}\left(\left(\partial D_{S} / \partial P_{g}\right)\left(\partial P_{g}^{*} / \partial n\right)\right) \\
& \left(\left(\partial D_{L} / \partial A\right)+\left(\partial D_{S} / \partial A+\left(\partial D_{S} / \partial P_{g}\right)\left(\partial P_{g}^{*} / \partial A\right)\right) .\right.
\end{aligned}
$$

The second r.h.s. term in parentheses in (A7) is the effect of entry on the reduced-form demand response to advertising. By Young's theorem, this is also the effect of advertising on the reduced-form demand response to entry. Also note that $\left[A^{b}\right]$ is $<0$ by the second-order conditions.

Using these expressions, we can write the following results, based on total differentiation of equations (3a) and (3b) in the text, for the effects of entry on equilibrium brand-name price and advertising:

$$
\begin{aligned}
d P_{b} / d n & =\left\{\left[A^{b}\right]\left[n^{a}\right]-\left[A^{a}\right]\left[n^{b}\right]\right\} /\left\{\left[A^{a}\right]^{2}-\left[P^{a}\right]\left[A^{b}\right]\right\} \\
d A / d n & =\left\{\left[A^{a}\right]\left[n^{a}\right]-\left[P^{a}\right]\left[n^{b}\right]\right\} /\left\{\left[P^{a}\right]\left[A^{b}\right]-\left[A^{a}\right]^{2}\right\} .
\end{aligned}
$$

From the second-order conditions, we know that $\left[P^{a}\right]<0,\left[A^{b}\right]<0$, and the denominators of (A8) and (A9) are negative and positive respectively.

Predictions about the signs of $d P_{b} / d n$ and $d A / d n$ now depend upon the signs of $n^{a}, n^{b}$, and $A^{a}$ as shown in Appendix Table I. Under the maintained assumption that marginal costs are constant, $n^{a}$ consists of two terms (see equation (A4)). The second of these terms is the partial effect of entry on reduced-form brand-name demand (holding $P_{b}$ and $A$ constant); this must be negative. For $n^{a}$ to be positive, then, entry must have the effect of making the reduced-form brand-name demand curve steeper. Similarly, $A^{a}$ consists of two terms (equation (A5)) the first of which (the partial effect of advertising on reduced-form brand-name demand) is positive. For $A^{a}$ to be negative, advertising must make the reduced-form demand curve less- 
steeply sloped. Finally, with constant marginal costs $n^{b}$ (equation (A7)) contains only one term which is negative (positive) when advertising increases (decreases) the negative partial effect of entry on reduced-form brand-name demand.

\section{References}

1. Berndt, Ernest R., Zvi Griliches, and Richard G. Rosett. "On the Accuracy of Producer Price Indexes for Pharmaceutical Preparations: An Audit Based on Detailed Firm-Specific Data.” Working paper No. 3490, National Bureau of Economic Research, October 1990.

2. Bond, Ronald S. and David F. Lean. "Sales, Promotion, and Product Differentiation in Two Prescription Drug Markets." Staff Report to Federal Trade Commission. Washington, D.C.: Federal Trade Commission, 1977.

3. Caves, Richard E., Michael D. Whinston, and Mark A. Hurwitz, "Patent Expiration, Entry and Competition in the U.S. Pharmaceutical Industry: An Exploratory Analysis." Brookings Papers on Economic Activity, Forthcoming 1992.

4. Comanor, William S. "The Political Economy of the Pharmaceutical Industry." Journal of Economic Literature, September 1986.

5. Doering, P. H. et al. "Therapeutic Substitution in the HMO Outpatient Environment." Drug Intelligence and Clinical Pharmacy, Volume 22, 125-30, 1988. June 1954.

6. Dorfman, Robert and Peter Steiner, "Optimal Advertising and Optimal Quality." American Economic Review,

7. Dranove, David, "Medicaid Formulary Restrictions." Journal of Law and Economics, April 1989.

8. Gold, Marsha et al. "Pharmacy Benefits in HMOs." Health Affairs, Fall 1989, 182-90.

9. Grabowski, Henry and John Vernon. "Brand Loyalty, Entry and Price Competition in Pharmaceuticals After the 1984 "Drug Act”." Mimeo: Duke University, July 1990.

10. Hurwitz, Michael A. and Richard E. Caves, "Persuasion or Information? Promotion and the Shares of Brand Name and Generic Pharmaceuticals." Journal of Law and Economics, October, 1988.

11. Interstudy. The Interstudy Edge. Excelsior, Minnesota: 1989.

12. Kuschner Dan, and Reuben Fierman, "Slowdown Continues in Rx Department Gains." American Druggist, 1986, 193(5) 80-84.

13. Lave, Judith R. "The Effect of the Medicare Prospective Payment System," in Annual Review of Public Health Vol. 10, edited by L. Breslow, J. Fielding and L. Lave. 1989.

14. Leffler, Keith B., "Persuasion or Information? The Economics of Prescription Drug Advertising." Journal of Law and Economics, April 1981.

15. Masson, Allison and Robert L. Steiner. "Generic Substitution and Prescription Drug Prices: Economic Effects of State Drug Product Selection Laws." Staff Report of the Bureau of Economics, U.S. Federal Trade Commission. Washington, D.C.: Federal Trade Commission, 1985.

16. Milgrom, Paul and John Roberts, "Limit Pricing and Entry Under Incomplete Information: An Equilibrium Analysis." Econometrica, March 1982, 443-60.

17. Rosenthal, Robert, "A Model in Which an Increase in the Number of Sellers Leads to a Higher Price." Econometrica September 1990, 1575-79.

18. Rosko, Michael D., "A Comparison Performance Under Partial Payer Medicare PPS and State All Payer RateSetting Systems." Inquiry, Winter 1989, 48-61.

19. Salop, Steven C., "Monopolistic Competition With Outside Goods." Bell Journal of Economics Spring 1979,

20. Satterthwaite, Michael, "Consumer Information, Equilibrium Industry Price, and the Number of Sellers." Bell Journal of Economics Autumn 1979, 483-502.

21. Schmalensee, Richard, "Product Differentiation Advantages of Pioneering Brands." American Economic Review, March 1982, 349-65.

22. Schwartzman, David. Innovation in the Pharmaceutical Industry. Baltimore: Johns Hopkins University Press, 1976.

23. Statman, Meier. "The Effect of Patent Expiration on the Market Position of Drugs,"in Drugs and Health: Economic Issues and Policy Objectives, edited by R. B. Helms. Washington: American Enterprise Institute for Public Policy Research, 1981.

24. Stolar Michael, “ASHP National Survey of Hospital Pharmaceutical Services 1987." American Journal of Hospital Pharmacy, April 1988, 801-18.

25. Tirole, Jean. The Theory of Industrial Organization. Cambridge, Mass.: The MIT Press, 1988.

26. United States Senate, Special Committee on Aging. Prescription Drug Prices: Are We Getting Our Money's Worth? Serial No. 101-D, USGPO:1989.

27. - Skyrocketing Prescription Drug Prices: Turning a Bad Deal Into a Fair Deal. Serial No. 101-F, USGPO: 1990. 
28. Wagner, Judith L. and Bridgette M. Duffy. "Containing the Costs of Prescription Drugs: The U.S. Experience." Paper Presented at the Symposium: Controlling Costs While Maintaining Health. Bonn, 1988.

29. Waterston Michael. Economic Theory of the Industry. Cambridge: Cambridge University Press, 1987.

30. Weiner, Jonathan P. et al. The Impact of HMOs on Ambulatory Care Pharmaceutical Use. Report Health Services Research and Development Center, Johns Hopkins University, November 1989.

31. Weston, J. Fred. "Pricing in the Pharmaceutical Industry." in Issues in Pharmaceutical Economics, edited by R. A. Chien. Lexington, Mass.: D.C. Health and Company, 1979. 